\title{
Experimental and numerical studies on the stability behavior of composite panels stiffened by tilting hat-stringers
}

\author{
Yi Wang · Fusheng Wang · Senqing Jia · Zhufeng Yue
}

\begin{abstract}
Due to the existence of sweepback angle of aircraft, the stringers of the stiffened panels in some parts may be declined instead parallel to the boundary. The paper deals with stability experiment investigation on the stiffened composite panels with tilting stringers. Two panels stiffened by six tilting stringers were manufactured and tested. Attempts were made to obtain the buckling load, ultimate load carrying capability and failure state of the panels. Finite element analysis was performed to investigate the tests and FE models were calculated by ABAQUS. The numerical results were assessed by comparing with the test data and good agreement was observed for both buckling and ultimate collapse load as well as the failure modes of the structure. Further investigation was performed to explore the influence of tilting angles on stability behavior of the panels which revealed that the buckling load exhibited a continuous decrease with the increasing tilting angles while the ultimate load showed an initial rise from $0^{\circ}$ to $1^{\circ}$ and then decreased.
\end{abstract}

Keywords Hat-stiffened panels; Stability experiment; Tilting stringers; Post-buckling;

Finite Element Method (FEM)

\section{Introduction}

Composite materials have been increasingly used in aerospace industry due to their considerable stiffness and strength to weight ratio as well as designable characteristics. Stiffened composite panel is a very typical form of composite structures which has been widely adopted in aircraft structures, like the fuselages, tail planes and wings. In practice, the composite panels are often subjected to axial compression which would easily lead to the buckling of the structures. Moreover, it is found and acknowledged that the stiffened panels

Corresponding author: Yi Wang

E-mail: wangyi_npu@hotmail.comＴel: +86 2988431002

Yi Wang, Fusheng Wang, Senqing Jia, Zhufeng Yue

School of Mechanics, Civil and Architecture, Northwestern Polytechnical University

Xi' an, 710129, P. R. China 
still have considerable load carrying capability in the post-buckling stage which has large potential for weight savings. However, up to now, there are still no specific guidelines available for post-buckling design of stiffened composite panels [1]. Therefore, it is crucial to study the stability behavior (buckling and post-buckling capacity) of stiffened panels.

Several research projects have been carried out to study the buckling and post-buckling characteristics of stiffened panels, like POSICOSS [2] and COCOMAT [3] conducted by European Committee. Many experiments and numerical simulations were carried out upon the stability behaviors of composite stiffened panels by researchers. B.G. Falzon et al. [4,5] experimentally investigated the buckling and post-buckling behavior of I-stiffened and hat-stiffened composite panels under uniaxial compression loads. L. Boni et al. [6] explored the post-buckling behavior of flat stiffened panels experimentally and numerically. The comparison between numerical and experimental results validated the FEM approach. $\mathrm{H}$. Abramovich et al. [7] investigated the buckling behavior of composite laminate stiffened panels under combined shear-axial compression. The results indicated the torsion-carrying capability was dependent on stringer geometry and layup. H. K. Jain et al. [8] conducted FE studies on the buckling behavior of laminated composite panels with different stiffeners (blade-, angle-, T- and hat-stiffened) subjected to in-plane shear loading and developed some guidelines for better stiffener proportioning. R. Zimmermann et al. [9] studied the buckling and post-buckling of stiffened CFRP curved panels and investigated the influence of planar thickness and stringer numbers. N. J. Kumar et.al [10] performed post-buckling analysis of stiffened panel by nonlinear finite element analysis and the effects of ply-orientation, different composite materials as well as the stiffener numbers were studied. G. H. Rahimi et al. [11] analyzed the effect of stiffener profile on buckling strength of composite stiffened panels under axial loading. Results showed that stiffening the shells increased the buckling load while decreased the buckling load to weight ratio. Besides the stability behavior of the panels under different loading conditions (i.e. compression and shear) and the related parameters (i.e. stiffener profile and numbers) research, the ultimate failure state in post-buckling stage was also emphasized by many researchers [12-13].

However, in current stability researches of stiffened composite panels, the stiffeners are commonly parallel to the lateral side of the skin. While with the development of aircraft 
design concept and composite manufacture techniques, in current engineering design, like the design of Unmanned Aerial Vehicle (UAV), the wing fuselage integration design and manufacture method is adopted which commonly result in declined stiffeners at central wing part, as shown in Fig.1. Compared with traditional design of wing structures, the integration design and manufacture of the wing structures has less structural components and much easier assembly operations as well as better aeroelastic performance. However, for the central wing part of this kind of structures which is a novel one, few researches are carried out to investigate their stability characteristics. Considering the wing fuselage integration design and manufacture has become one of the tendencies in aircraft design, it is necessary to study the stability characteristics of this kind of structure for better structural efficiency. In this paper, the stability behaviors of composite panels stiffened by tilting stringers were experimentally investigated and numerically analyzed. Two test panels were manufactured and axial compressive experiment of the structure was conducted. The corresponding numerical simulation was carried out using finite element method. The failure judgment and progressive damage of the composite materials were achieved by USDFLD coding and the shear nonlinear effect was considered in the damage criterion. The buckling load, ultimate load carrying capability and failure state of the panel were predicted and compared with the experimental results. Further exploration was conducted to investigate the influence of tilting stringers on structural stability capability.

\section{Stability experiment of composite stiffened panels}

\subsection{Experimental set up}

The test specimens were flat panels made of carbon fiber reinforced composite and stiffened by six tilting stringers with hat-shaped cross section laying symmetrically along the longitudinal direction, as shown in Fig.2 and 3.

Two specimens were tested and numbered by Panel A and Panel B. The nominal width (W) and length (L) of the panel were $740 \mathrm{~mm}$ and $1400 \mathrm{~mm}$, respectively. There was $45 \mathrm{~mm}$ length from each end at the longitudinal direction reinforced by epoxy resin blocks with steel frames in four sides of each block. The interval between two stiffeners was $194 \mathrm{~mm}$. The tilting angle was defined as the angle between the stiffener axis and the horizontal lines, 
which was $6.5^{\circ}$. The panels were made of $3234 / \mathrm{T} 700$ composite. The skin consisted of a $36-p l y ~ l a m i n a t e ~ w i t h ~ l a y-u p ~ c o n s e q u e n c e ~ o f ~\left[ \pm 45 / 0_{2} / 45 / 0_{2} /-45 / 0 / 45 / 90 /-45 / 0_{2} / 45 / 90 /-45 / 0\right]_{\mathrm{S}}$ for a total nominal thickness of $4.5 \mathrm{~mm}$ while the stringers were composed of a 20-ply laminate with the stacking sequence of $\left[ \pm 45 / 0_{3} / 45 / 90 /-45 / 0_{2}\right]_{\mathrm{S}}$ for a nominal total thickness of $2.5 \mathrm{~mm}$. The middle joint parts which were used to reinforce the connection of two tilting stiffeners were made of aluminum for a thickness of $2 \mathrm{~mm}$. The mechanical properties of the materials are shown in Table 1 and 2. The skin and stringers are co-cured in an autoclave.

The axial compression tests were performed on hydraulic test machine with four-column frames and a maximum $1000 \mathrm{kN}$ load sensor accurate at $1 \%$ on the test range. The specimen was clamped at the top and bottom while the two lateral sides were simply supported by constrained with C-shape cross section jigs, as shown in Fig.4. The displacement of the panel was recorded as the movement of the machine's crosshead and a camera was set to record the experiment process. The strain gauges were installed back to back at the surface of the skin and stringers to measure the strains of the panel during compression test. The locations of the 53 strain gauges are shown in Fig.5, the numbers in bracket represent the ones located on the opposite side.

Before the experiment, the trial tests were carried out to guarantee the panels were uniformly loaded by checking the consistence between the strains of back to back measure points on the skin. System alignment was also checked to eliminate the excess bending of the test specimen from the test system. The compression tests were performed through controlling the force applied on the loading end (top platform of the test machine). In order to satisfy the ideal static test condition and detect any damage during the loading process, the applied force increased gradually with $5 \%$ every step before $70 \%$ of the linear bucking load and subsequently reduced to $2 \%$ every step until the panel was collapsed.

\subsection{Experimental results}

Panel A was tested first. A small cracking noise was heard when the load increased to $422.5 \mathrm{kN}$, but no visual damage can be observed. The cracking sound burst out again until the loading increased to $653.2 \mathrm{kN}$. Eventually, collapse occurred at load value of $767.3 \mathrm{kN}$ accompanied with a very loud noise. The whole structure became collapsed along with the 
breakage of fibers and matrix, delamination and tearing of the skin. Panel B exhibited a similar behavior.

The strain load curves of the panels with the increasing of the applied load were obtained during the compression test and the initial buckling load of the structure was determined by the split point of back-to-back strain-load curves. Three back-to-back points' strains at typical locations of the skin (G1/G17, G8/G24, and G11/G27) were chosen to exhibit the strain evolution of the panels under compression, as shown in Fig.6-8. From the plots it can be seen that for panel A, the strains are straightly increased with the raising of the applied load and almost the same for back-to-back points till the buckling occurs at the load value of around $375 \mathrm{kN}$. While for panel B, the strain of the back-to-back points are not that close in the evolution process which may be caused by the error of the specimen setup or "potted region" manufactured. There is no obvious split point of the strain-load curves which indicate that there is no apparent buckling occurs of the panel B.

Fig.9 shows the load vs. displacement curves of the compression test. It can be seen that the load linearly increases up to about $375 \mathrm{kN}$ for panel A and $350 \mathrm{kN}$ for panel B which are corresponding to the buckling loads obtained from the strain-load curves. The buckling phenomenon of panel B is less obvious than panel A according to the load vs. displacement curves which is consistent with the strain-load curves above. Then the carrying load still rises with the increase of the displacement while the increasing rate decreases until reaching of the final collapse load. It can be obtained through the experiment that the Panel A has load carrying capability of $767.3 \mathrm{kN}$, higher than the load carrying capability for panel B which is $716.5 \mathrm{kN}$. This may be caused by the difference and imperfections during the manufacturing and curing process.

\section{Numerical analysis and verification of the test panels}

\subsection{Finite element analysis of the panel}

In this paper, the stability behavior of the panel with tilting stringers was simulated by the commercial finite element software ABAQUS. Buckling and post-buckling characteristics of the panel were analyzed and predicted. Before the numerical analysis, a necessary mesh refinement was adopted to capture the nonlinear effect and guarantee the convergence during 
the simulations. A relatively fine mesh with more than 15000 elements was used for the computations, as shown in Fig.10. The skin and the stringers as well as the middle connections were modeled with S4R element. The interface of the skin-stiffener was simulated by cohesive element.

The boundary condition of the structure was set to be consistent with the experiment. The loaded end was free to move in the axial direction while all the other degrees of freedom were constrained. The clamp end was constrained in all six degrees of freedom and the other two lateral sides were simply supported with lateral and out of plate displacement fixed. The load was applied as an axial displacement on the centroid point of loaded end. The loaded end region is coupled to the centroid point by "coupling constraints" to guarantee a uniform loading simulation.

The linear buckling analysis of the panels was carried out first and the initial bucking load and mode shapes of the structure were obtained. In the subsequent nonlinear post-buckling analysis, the progressive degradation of composite material was applied for more accurate prediction of the ultimate collapse load and failure state of the panel [14]. The Hashin's damage initiation criterion, which is widely used in industry, was adopted to predict the onset of composite material's damage in this paper. Since for the tilting stiffeners under compression, the load on tilting stiffeners can be divided into the compression load along the stiffener direction and shear force vertical to the stiffener. The shear effects should be emphasized in the analysis. Some revisions of the Hashin's failure criterion are made in this paper to consider the nonlinear shear effects.

When the nonlinear effect of a lamina is considered, the constitutive relationship can be expressed in the following form:

$$
\gamma_{12}=\left(\frac{1}{G_{12}^{0}}\right) \tau_{{ }_{1} \frac{1}{2}} \alpha \tau^{3}
$$

In order to be inserted into the finite element program, the expression above is converted into a linear form as follows:

$$
\tau_{12}^{(i+1)}=G_{12} \gamma_{12}^{(i+1)}=(1-d) G_{12}^{0} \gamma_{12}^{(i+1)}
$$




$$
d=\frac{3 \alpha G_{12}^{0}\left(\tau_{12}^{(i)}\right)^{2}-2 \alpha\left(\tau_{12}^{(i)}\right)^{2} / \gamma_{12}^{(i)}}{1+3 \alpha G_{12}^{0}\left(\tau_{12}^{(i)}\right)^{2}}
$$

Where $\gamma_{12}$ is the shear strain, $\tau_{12}$ is the shear stress, $G_{12}^{0}$ is the initial shear modulus, $\alpha$ is the nonlinear shear coefficient, $d$ is the damage variable. With the increasing of the applied load, the shear modulus decreases gradually. When we consider the nonlinear shear effect $\alpha \neq 0$ while $\alpha=0$ when the nonlinear shear effect is ignored.

The modified Hashin's damage initiation criterion incorporated the nonlinear effect was shown Table 4, where $\sigma_{1}, \sigma_{2}, \tau_{12}$ are the stress components, $X_{t}, X_{c}, Y_{t}, Y_{c}$ are the tension and compression strength in longitudinal and transverse direction respectively, $S_{c}$ is the in-plane shear strength, $\alpha=0.25$ is used in analysis. When the damage initiation criterion was satisfied, a stiffness reduction method was used and further loading caused a complete loss of the stiffness, as shown in Table 4. The damage evolution law is based on the fracture energy dissipated during the damage process. ABAQUS USDFLD material user subroutine was used for coding and implemented to define the Hashin's damage initiation criterion and corresponding stiffness reduction of the materials upon satisfaction of the damage criterion. The elastic constants and the strength properties for Hashin's damage criterion are listed in Table 1 . The cohesive element $[15,16]$ was used to simulate the mechanical behavior of the adhesive and debonding failure mode of the skin-stiffener interface. A bilinear traction-separation constitutive law with linear softening [17] was used to represent the mechanical response of the adhesive. And the quadratic nominal strain failure criterion [17] and Power Law criterion [18] were adopted to evaluate the initial damage and crack propagation, respectively. The material properties of the adhesive used are presented in Table 3.

Considering the error between the real panels and the perfect models, imperfection was introduced in the post-buckling analysis by the addition of a combination of the eigenvectors obtained from the linear buckling analysis. In this paper, the first three buckling modes were used to import the imperfection of geometry and the factors of the modes selected had a maximum perturbation magnitude of about $10 \%, 5 \%$ and $5 \%$ of the skin thickness, 
respectively. Modified Riks algorithm was adopted for the non-linear post-buckling analysis for its better handling of the snap-through post-buckling deformation.

\subsection{Numerical results and discussion}

The load-shortening curves and out of plane deflections of the specimen under axial compression are shown in Fig. 11. The results were normalized using the end-shorting (Ucr) at the buckling load for better comparison. A good agreement was observed between the numerical and experimental results for the prediction of initial buckling load and ultimate load of the structure with error less than $7 \%$. The latter one is almost two times of the critical buckling load for both the experimental tests and numerical results, which demonstrated the postbuckling capability of stiffened panel with tilting stringers. In the meantime, it indicated that the modified risks method combined with progressive damage theory and cohesive element can predict relatively reliable results for this kind of structure. The value of the buckling load simulated is $384.9 \mathrm{kN}$ which is a bit greater than that of the test results. This may be caused by the finite element model of the panel was considered perfect in the linear buckling analysis stage. The ultimate collapse loads after buckling are about twice of the buckling loads in tests as well as numerical simulation while the load-carrying capability of panel obtained in numerical analysis is lower than that of experimental results. This is possibly because the progressive degradation method adopted in the paper that the stiffness reduction to zero produced a relatively conservative result. From the out of plane deflections, it can be seen the panel in this paper exhibits a central global buckling under axial compression instead of local buckling between stiffeners. This is possibly related to the stiffness ratio of skin and stiffeners for stiffeners are not that 'strong'. The displacement of the panel is larger than that of the experimental results and compared with the experimental load-displacement curves, there is a more apparent turning point at the buckling load in numerical curve.

The collapse state of the panels obtained from the numerical results is compared with the experiments in Fig.12. The elements in red represent those in failure. A good agreement with the experiments can be found. It can be seen that in the final collapse state, the panel exhibits 
various types of failure including the fiber fracture in both the stiffeners and skin, matrix cracking in the skin and multiple delaminations in the region between the skin and stiffeners. Both the numerical simulation and experiment tests show that for panels stiffened by tilting stringers, the delamination between stiffeners and skin occurs first under compression, subsequently followed by fiber fracture and matrix cracking. In the meantime, compared with the other failure types, delamination is also the most serious failure type for this kind of stiffened panels. It may due to the stiffness ratio between the stiffeners and panels for this structure, the stiffened panel occurs global buckling directly without apparent local buckling stage. The occurrence of global buckling causes the large bending deflection of the stiffeners which results in the large deviation force on the interface between the stiffeners and panel. Also, since the loads on tilting stiffeners can be divided into compression along the stiffener and shear force vertical the stiffener, the shear force on stiffeners also intensifies the deviation of the stiffeners and panel. In consequence, the delamination occurs first and is the most serious failure state. With the increasing of the load, when the fiber and matrix meet the critical value, the failure of fiber and matrix follows until the collapse of the whole structure.

\subsection{Further investigation}

Further investigation and analysis were performed against the influence of tilting stringers on the panel's stability characteristics. Finite element method validated above was used and 8 panels stiffened by tilting stiffeners varying from $0^{\circ}$ to $8^{\circ}$ were constructed and analyzed given the range of aircraft sweepback angles. All the other configurations and material properties were the same as the panel analyzed above.

The analysis results were shown in Fig.13. From the results, it can be concluded that the buckling mode and collapse state of the panel stiffened by tilting stiffeners change little with the variation of tilting angles, while the buckling loads and ultimate loads change much. It can be seen that buckling loads of the panels exhibit a continuous decrease with the increase of tilting angles while the ultimate load carrying capability shows an initial rise from $0^{\circ}$ to $1^{\circ}$ and then decreases. The results reveal that though the wing fuselage integration design and manufacture has lots of advantages, the stability capability of the structures will commonly decrease, which can provide a valuable reference for practical design of aircraft.

\section{Conclusions}


This paper performed stability experiments and numerical simulations on panels stiffened by tilting stringers. Two panels with six tilting stringers were manufactured and tested under axial compression. Nonlinear shear effects and the progressive damage of the material as well as the delamination of the interface between the stiffener and skin were considered and achieved in the numerical simulation. The main results are as follows:

(1) Both the stability experiment and the numerical results demonstrate the post-buckling capability of this kind of structure. The ultimate load carrying capability is about two times of the buckling load for the panel in test while it is nearly 1.9 times of the panel in numerical simulation result.

(2) The numerical simulation load-shortening curve was compared with the experimental results revealing a good prediction up to the onset of the critical buckling load and collapse load of the panel stiffened with tilting stringers with error less than $7 \%$.

(3) The panel exhibits various failure types in ultimate collapse state and the simulation result is consistent with the tests. The analysis results indicate that for panels stiffened by tilting stringers under compression, the delamination between skin and stiffeners occurs first and is the most serious failure type.

(4) Compared with the panel stiffened by straight stiffeners, the buckling mode and collapse state of the panel stiffened by tilting stringers change little while the buckling load exhibits a continuous decrease with the increase of tilting angles. The ultimate load shows an initial increase from $0^{\circ}$ to $1^{\circ}$ and then decreases.

Acknowledgements This study is supported by the National Science Foundation of China (No: 51475369).

\section{References}

[1] Degenhardt R, Castro S G P, Arbelo M A, et al. Future structural stability design for composite space and airframe structures[J]. Thin-Walled Structures 81, 29-38 (2014). doi:10.1016/j.tws.2014.02.020

[2] Zimmermann R, Rolfes R. POSICOSS - improved postbuckling simulation for design of fibre composite stiffened fuselage structures[J]. Composite Structures 73(2), 171-174 (2006). 
doi:10.1016/j.compstruct.2005.11.041

[3] Degenhardt R, Rolfes R, Zimmermann R, et al. COCOMAT_improved material exploitation of composite airframe structures by accurate simulation of postbuckling and collapse[J]. Composite Structures 73(2), 175-178 (2006). doi:10.1016/j.compstruct.2005.11.042

[4] Falzon B G. The behaviour of damage tolerant hat-stiffened composite panels loaded in uniaxial compression[J]. Composites Part A: Applied Science and Manufacturing 32(9), 1255-1262 (2001). doi:10.1016/S1359-835x(01)00074-4

[5] Falzon B G, Stevens K A, Davies G O. Postbuckling behaviour of a blade-stiffened composite panel loaded in uniaxial compression[J]. Composites Part A: applied science and manufacturing 31(5), 459-468 (2000). doi:10.1016/S1359-835x(99)00085-8

[6] Boni L, Fanteria D, Lanciotti A. Post-buckling behaviour of flat stiffened composite panels: Experiments vs. analysis[J]. Composite Structures 94(12), 3421-3433 (2012). doi:10.1016/j.compstruct.2012.06.005

[7] Abramovich H, Weller T, Bisagni C. Buckling behavior of composite laminated stiffened panels under combined shear-axial compression[J]. Journal of Aircraft 45(2), 402-413 (2008). doi:10.2514/1.27635

[8] Jain H K, Upadhyay A. Buckling behavior of blade-, angle-, T-, and hat-stiffened FRP panels subjected to in-plane shear[J]. Journal of Reinforced Plastics and Composites 29(24), 3614-3623 (2010). doi:10.1177/0731684410383450

[9] Zimmermann R, Klein H, Kling A. Buckling and postbuckling of stringer stiffened fibre composite curved panels-tests and computations[J]. Composite Structures 73(2), 150-161 (2006). doi:10.1016/j.compstruct.2005.11.050

[10]Anyfantis K N, Tsouvalis N G. Post Buckling Progressive Failure Analysis of Composite Laminated Stiffened Panels[J]. Applied Composite Materials 19(3-4), 219-236 (2012). doi:10.1007/s10443-011-9191-1

[11]Rahimi G H, Zandi M, Rasouli S F. Analysis of the effect of stiffener profile on buckling strength in composite isogrid stiffened shell under axial loading[J]. Aerospace science and technology 24(1), 198-203 (2013). doi:10.1016/j.ast.2011.11.0072013.

[12]Orifici A C, de Zarate Alberdi I O, Thomson R S, et al. Compression and post-buckling damage growth and collapse analysis of flat composite stiffened panels[J]. Composites 
Science and Technology 68(15), 3150-3160 (2008). doi:10.1016/j.compscitech.2008.07.017

[13]Bisagni C, Cordisco P. Post-buckling and collapse experiments of stiffened composite cylindrical shells subjected to axial loading and torque[J]. Composite Structures 73(2), 138-149 (2006). doi:10.1016/j.compstruct.2005.11.055

[14]Anyfantis K N, Tsouvalis N G. Post Buckling Progressive Failure Analysis of Composite Laminated Stiffened Panels[J]. Applied Composite Materials 19(3-4), 219-236 (2012). doi:10.1007/s10443-011-9191-1

[15]Dávila C G, Camanho P P, Turon A. Effective simulation of delamination in aeronautical structures using shells and cohesive elements[J]. Journal of Aircraft 45(2), 663-672 (2008). doi:10.2514/1.32832

[16]Harper P W, Hallett S R. Cohesive zone length in numerical simulations of composite delamination[J]. Engineering Fracture Mechanics 75(16), 4774-4792 (2008). doi:10.1016/j.engfracmech.2008.06.004

[17]Camanho P P, Davila C G, De Moura M F. Numerical simulation of mixed-mode progressive delamination in composite materials[J]. Journal of composite materials 37(16), 1415-1438 (2003). doi:10.1177/002199803034505

[18]Turon, A., Dávila, C.G., Camanho, P.P., Costa, J.: An engineering solution for mesh size effects in the simulation of delamination using cohesive zone models. Engineering Fracture Mechanics 74(10), 1665-1682 (2007). doi:10.1016/j.engfracmech.2006.08.025 


\section{Figure and Table captions}

Fig. 1. Sketch of an integrated design wing

Fig. 2. Configurations of the test panels

Fig. 3. Configurations of the stringers

Fig. 4. Test set-up

Fig. 5. Locations of the strain gages

Fig. 6. Evolution of strains at the typical location of the panel (G1/G17)

Fig. 7. Evolution of strains at the typical location of the panel (G8/G24)

Fig. 8. Evolution of strains at the typical location of the panel (G11/G27)

Fig. 9. Load-shortening curves of the test panels

Fig. 10. Finite element model of the test specimen

Fig. 11. Comparison between the experimental and numerical normalized load-shorting curves

Fig. 12. Collapse state of the panel

Fig. 13. The variation of buckling load and ultimate load with the changing of tilting angles

Table 1 The properties of the 3234/T700 composite material

Table 2 The properties of Aluminum material

Table 3 The properties of the adhesive material

Table 4 The failure criterion and property reduction of composite materials 


\section{Tables}

Table 1 The properties of the 3234/T700 composite material

\begin{tabular}{lclc}
\hline Material properties & Values & Material properties & Values \\
\hline $\mathrm{E}_{1}(\mathrm{GPa})$ & 128 & $\mathrm{X}_{\mathrm{T}}(\mathrm{MPa})$ & 2093 \\
$\mathrm{E}_{2}(\mathrm{GPa})$ & 8.7 & $\mathrm{X}_{\mathrm{C}}(\mathrm{MPa})$ & 870 \\
$\mathrm{G}_{12}=\mathrm{G}_{13}(\mathrm{GPa})$ & 4.0 & $\mathrm{Y}_{\mathrm{T}}(\mathrm{MPa})$ & 50 \\
$\mathrm{G}_{23}(\mathrm{GPa})$ & 4.0 & $\mathrm{Y}_{\mathrm{C}}(\mathrm{MPa})$ & 198 \\
$v_{12}$ & 0.32 & $\mathrm{~S}(\mathrm{MPa})$ & 104 \\
\hline
\end{tabular}

Table 2 The properties of aluminum material

\begin{tabular}{lclc}
\hline Material properties & Values & Material properties & Values \\
\hline Elastic Modulus E $(\mathrm{GPa})$ & 69.58 & Density $\rho\left(\mathrm{g} / \mathrm{mm}^{3}\right)$ & 2.78 \\
Poisson's Ratio $v$ & 0.33 & & \\
\hline
\end{tabular}

Table 3 The properties of the adhesive material

\begin{tabular}{lclc}
\hline Material properties & Values & Material properties & Values \\
\hline $\mathrm{K}_{\mathrm{nn}}(\mathrm{MPa})$ & 2000 & $G_{t}(\mathrm{~N} / \mathrm{mm})$ & 0.4 \\
$\mathrm{~K}_{\mathrm{ss}}(\mathrm{MPa})$ & 751 & $\varepsilon_{n}^{0}$ & $2.5 \mathrm{e}-5$ \\
$\mathrm{~K}_{\mathrm{tt}}(\mathrm{MPa})$ & 751 & $\varepsilon_{s}^{0}$ & $6.5 \mathrm{e}-5$ \\
$G_{n}(\mathrm{~N} / \mathrm{mm})$ & 0.4 & $\varepsilon_{t}^{0}$ & $6.5 \mathrm{e}-5$ \\
$G_{s}(\mathrm{~N} / \mathrm{mm})$ & 0.4 & $\eta$ & 2 \\
\hline
\end{tabular}


Table 4 The failure criterion and property reduction of composite materials

\begin{tabular}{|c|c|c|}
\hline Failure type & Damage Initiation Criterion & Property Reduced \\
\hline $\begin{array}{c}\text { Fiber tension } \\
\left(\sigma_{1} \geq 0\right)\end{array}$ & $e_{f}^{2}=\left(\frac{\sigma_{1}}{X_{t}}\right)^{2}+\frac{2 \tau_{12}^{2} / G_{12}^{0}+3 \alpha \tau_{12}^{4}}{2 S_{C}^{2} / G_{12}^{0}+3 \alpha S_{C}^{4}}$ & $E_{11}, \mu_{12} \rightarrow 0$ \\
\hline $\begin{array}{c}\text { Fiber compression } \\
\left(\sigma_{1}<0\right)\end{array}$ & $e_{f}^{2}=\left(\frac{\sigma_{1}}{X_{C}}\right)^{2}$ & \\
\hline $\begin{array}{c}\text { Matrix tension } \\
\left(\sigma_{2} \geq 0\right)\end{array}$ & $E_{m}^{2}=\left(\frac{\sigma_{2}}{Y_{t}}\right)^{2}+\frac{2 \tau_{12}^{2} / G_{12}^{0}+3 \alpha \tau_{12}^{4}}{2 S_{C}^{2} / G_{12}^{0}+3 \alpha S_{C}^{4}} \mu_{12} \rightarrow 0$ \\
\hline Matrix Compression & $e_{m}^{2}=\left(\frac{\sigma_{2}}{Y_{C}}\right)^{2}+\frac{2 \tau_{12}^{2} / G_{12}^{0}+3 \alpha \tau_{12}^{4}}{2 S_{C}^{2} / G_{12}^{0}+3 \alpha S_{C}^{4}}$ & \\
\hline$\left(\sigma_{2}<0\right)$ & $e_{f m}^{2}=\left(\frac{\sigma_{1}}{X_{C}}\right)^{2}+\frac{2 \tau_{12}^{2} / G_{12}^{0}+3 \alpha \tau_{12}^{4}}{2 S_{C}^{2} / G_{12}^{0}+3 \alpha S_{C}^{4}}$ & $G_{12}, \mu_{12} \rightarrow 0$ \\
\hline Fiber-Matrix Shear & & \\
\hline$\left(\sigma_{1} \leq 0\right)$ & & \\
\hline
\end{tabular}




\section{Figures}

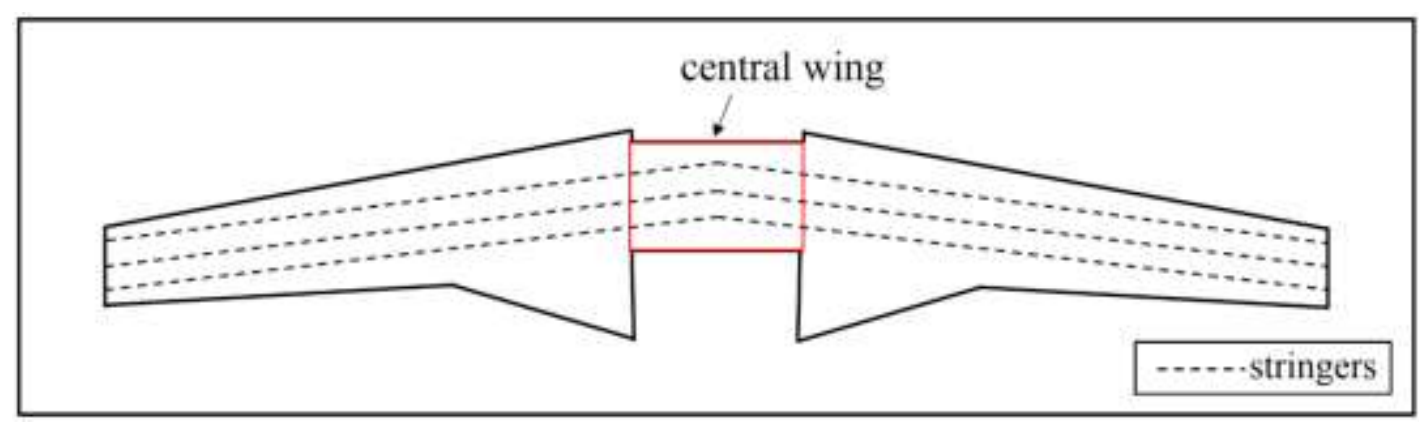

Fig. 1. Sketch of an integrated design wing

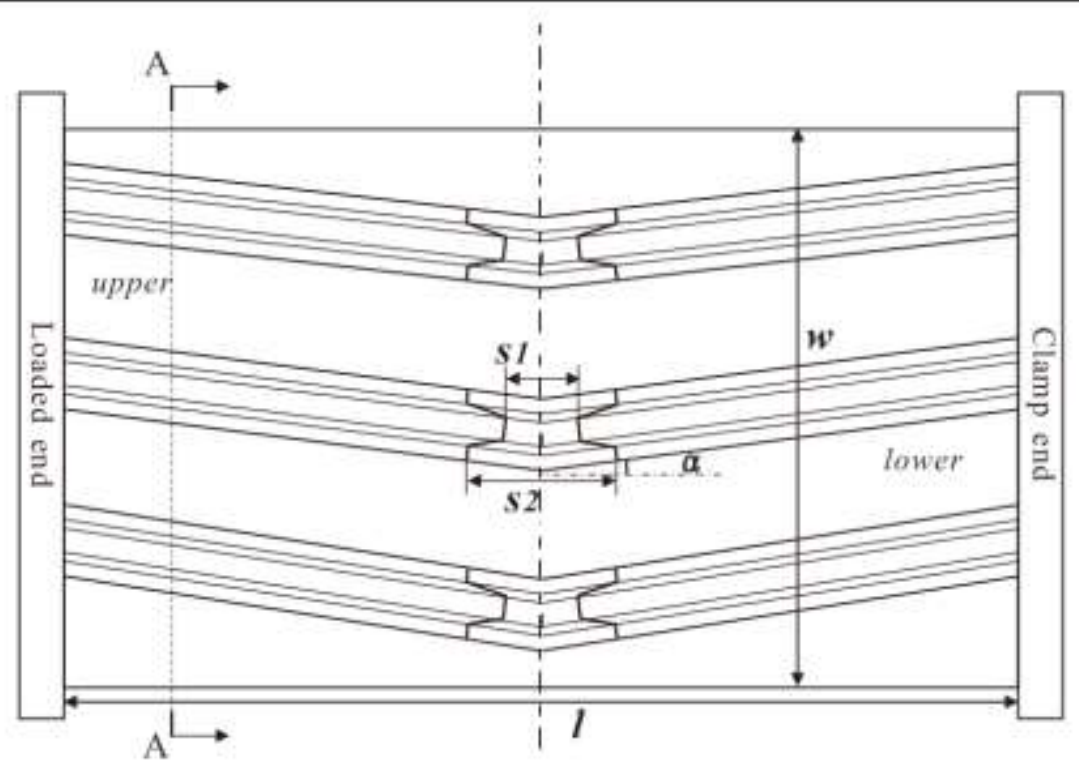

Section A-A

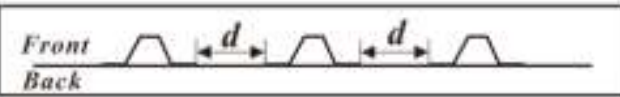

Fig. 2. Configurations of the test panels 


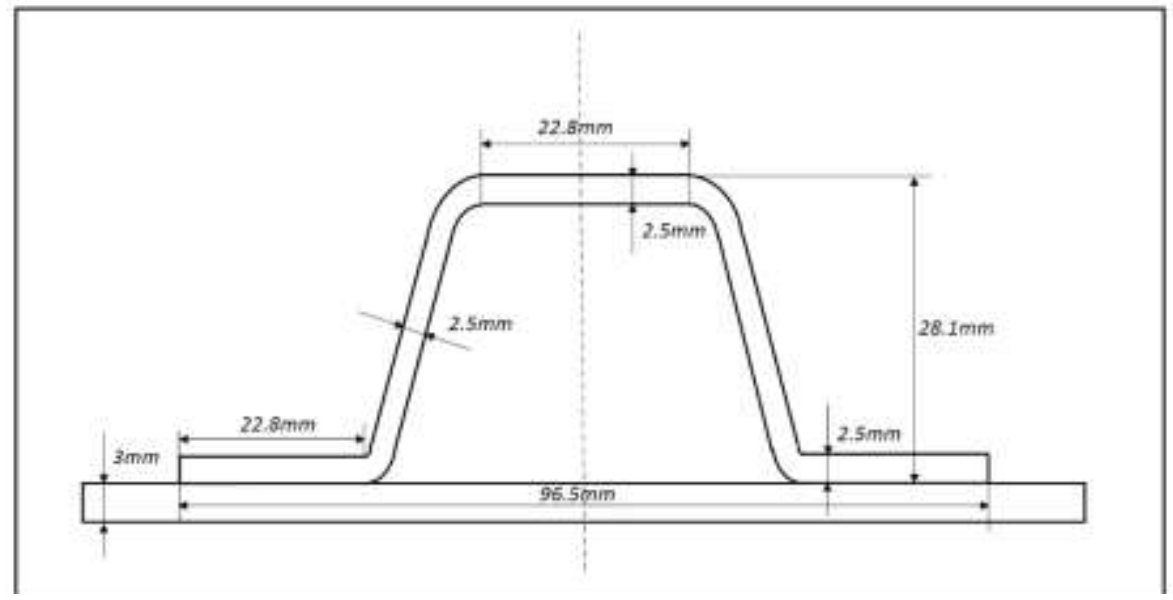

Fig. 3. Configurations of the stringers
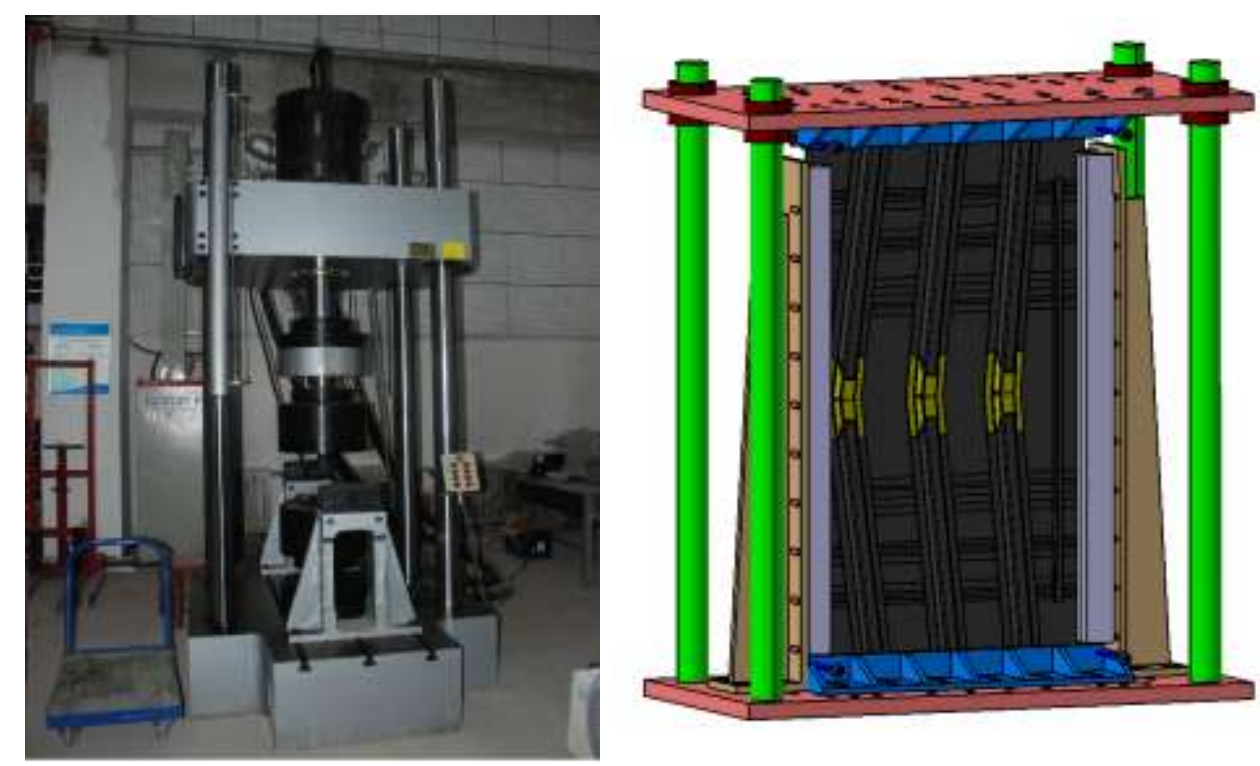

Fig. 4. Test set-up. Left: test machine. Right: the set-up of the specimen 


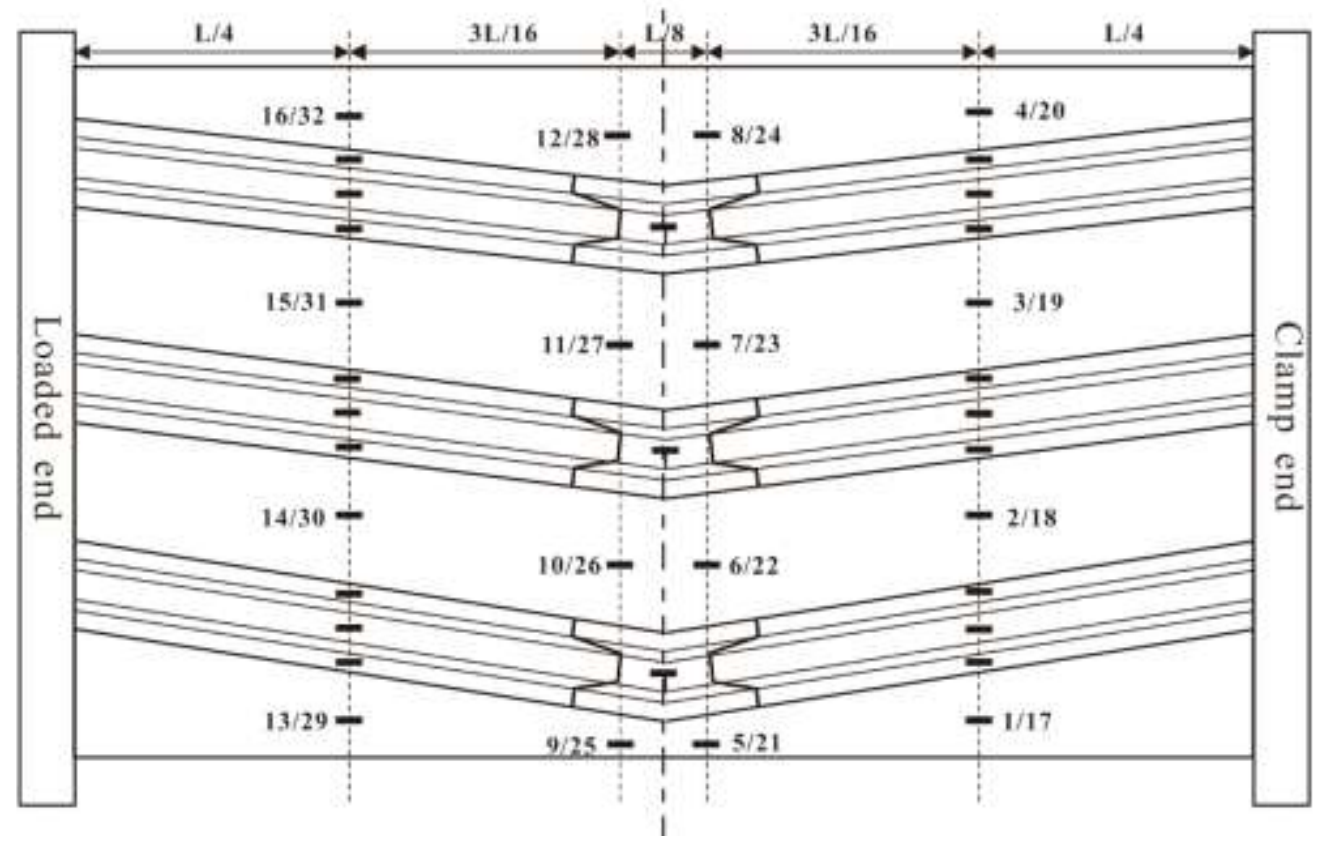

Fig. 5. Locations of the strain gages

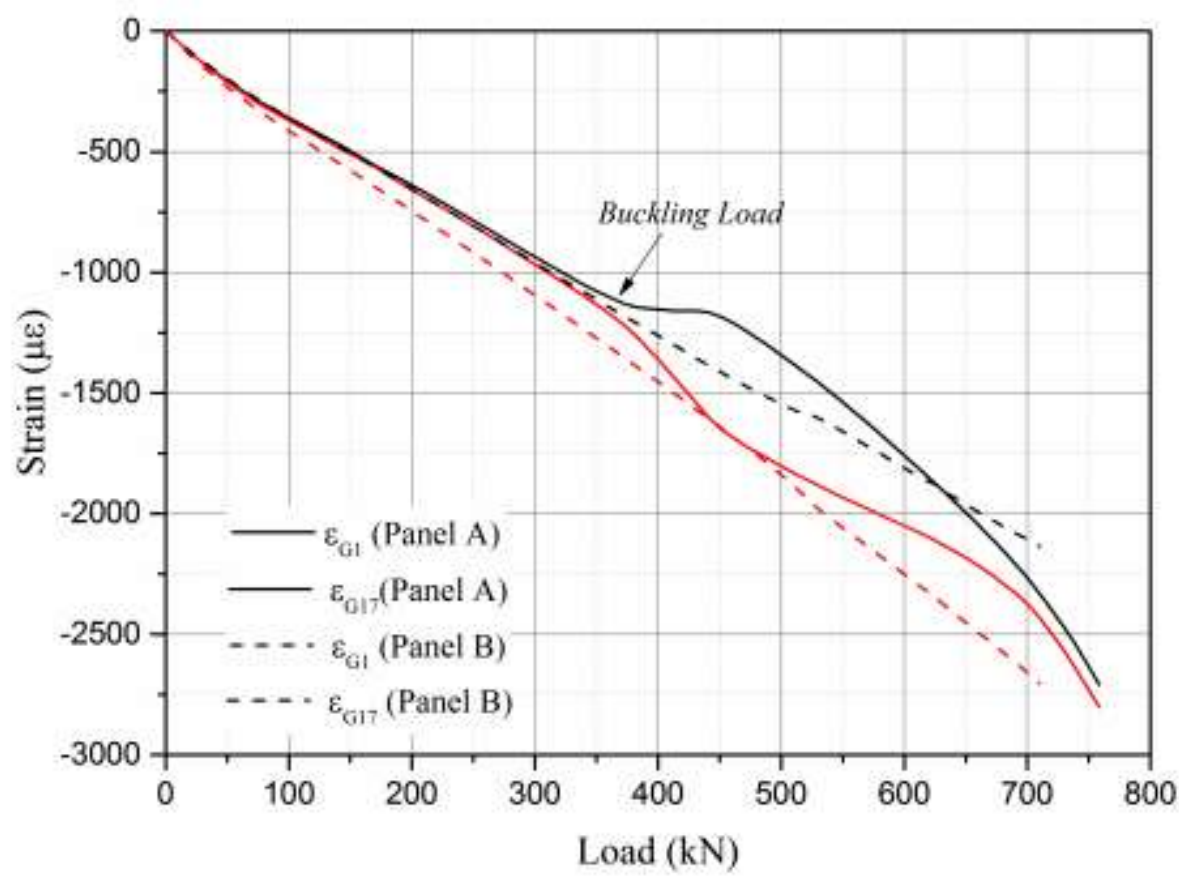

Fig. 6. Evolution of strains at the typical location of the panel (G1/G17) 


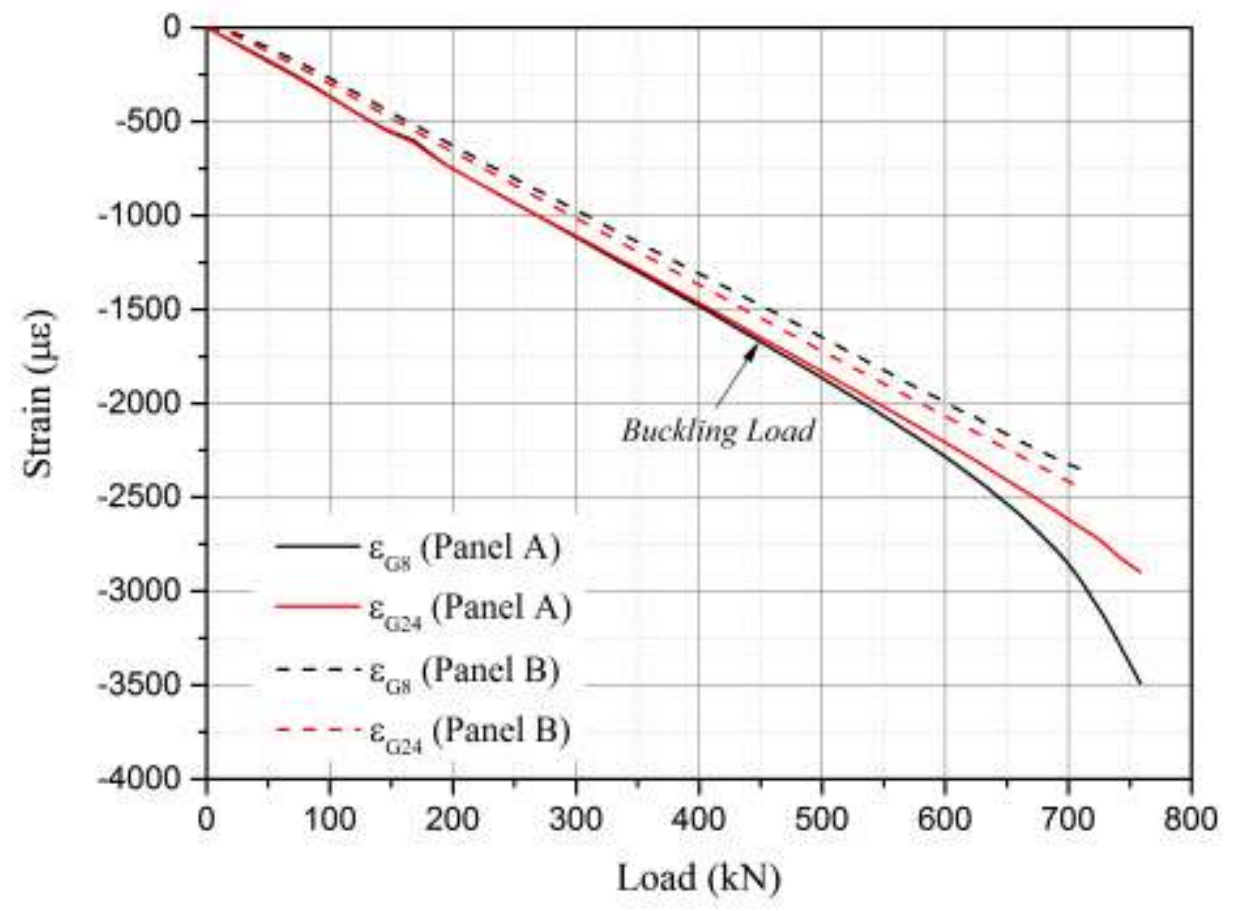

Fig. 7. Evolution of strains at the typical location of the panel (G8/G24)

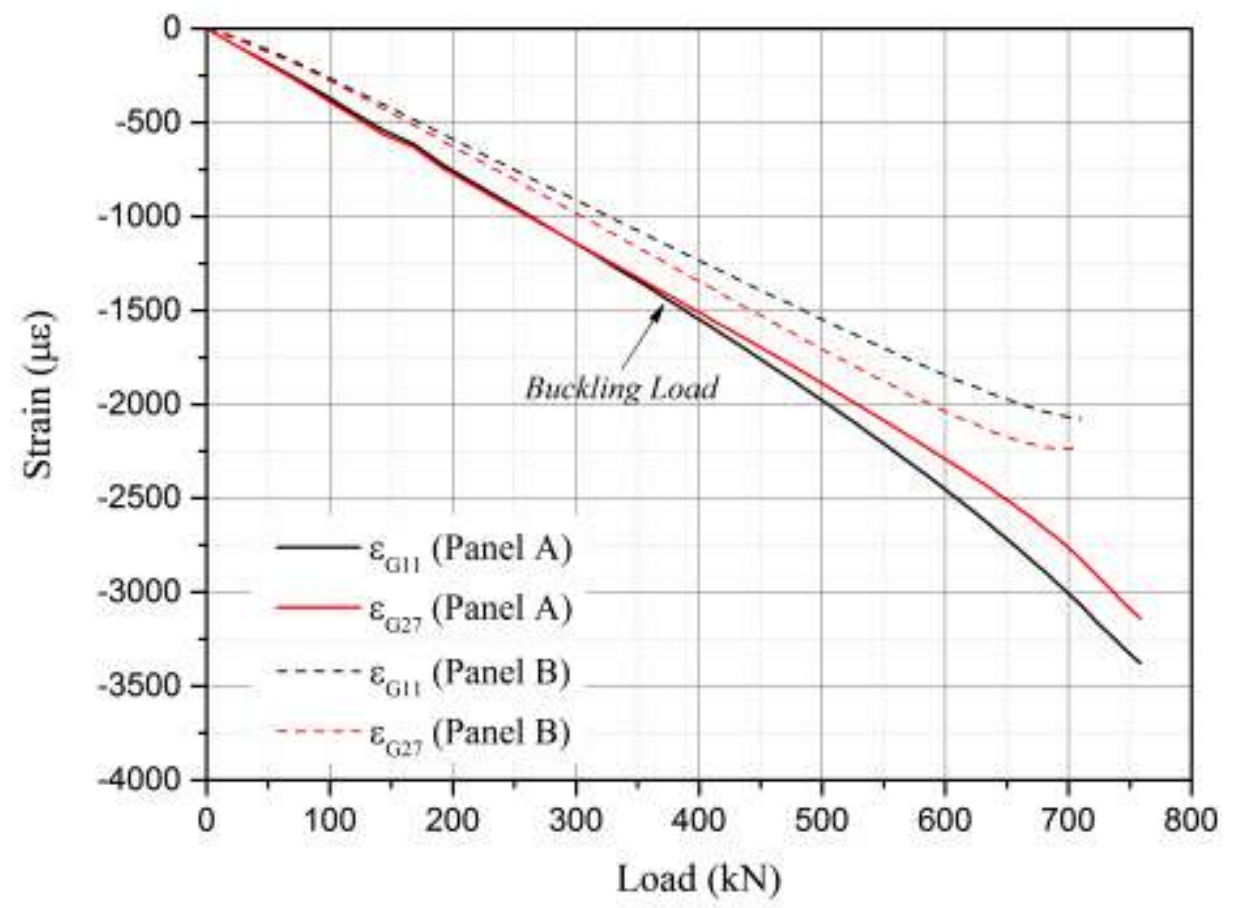

Fig. 8. Evolution of strains at the typical location of the panel (G11/G27) 


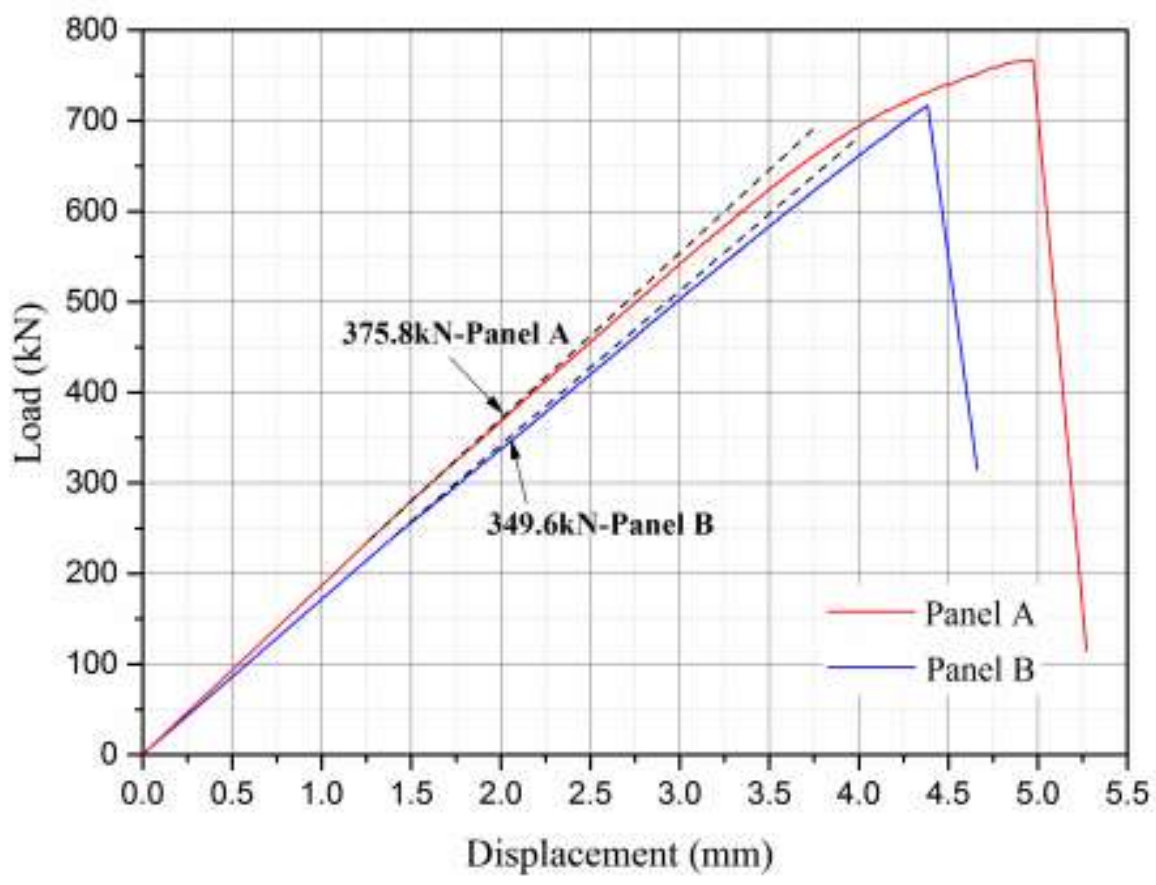

Fig. 9. Load-shortening curves of the test panels

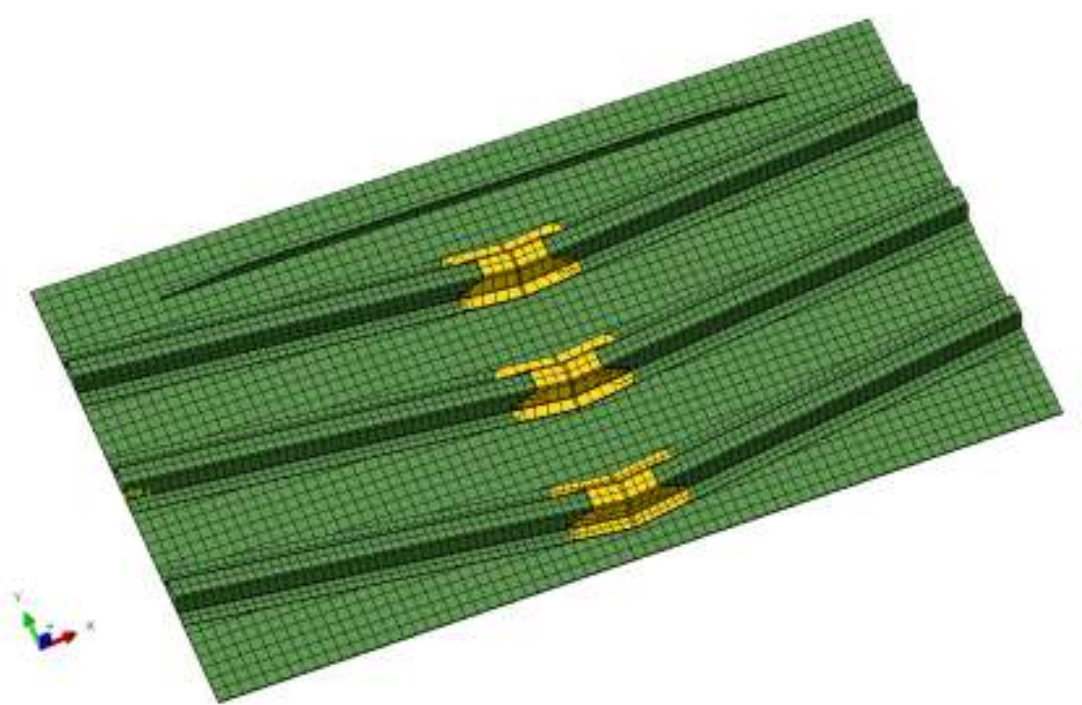

Fig. 10. Finite element model of the test specimen 


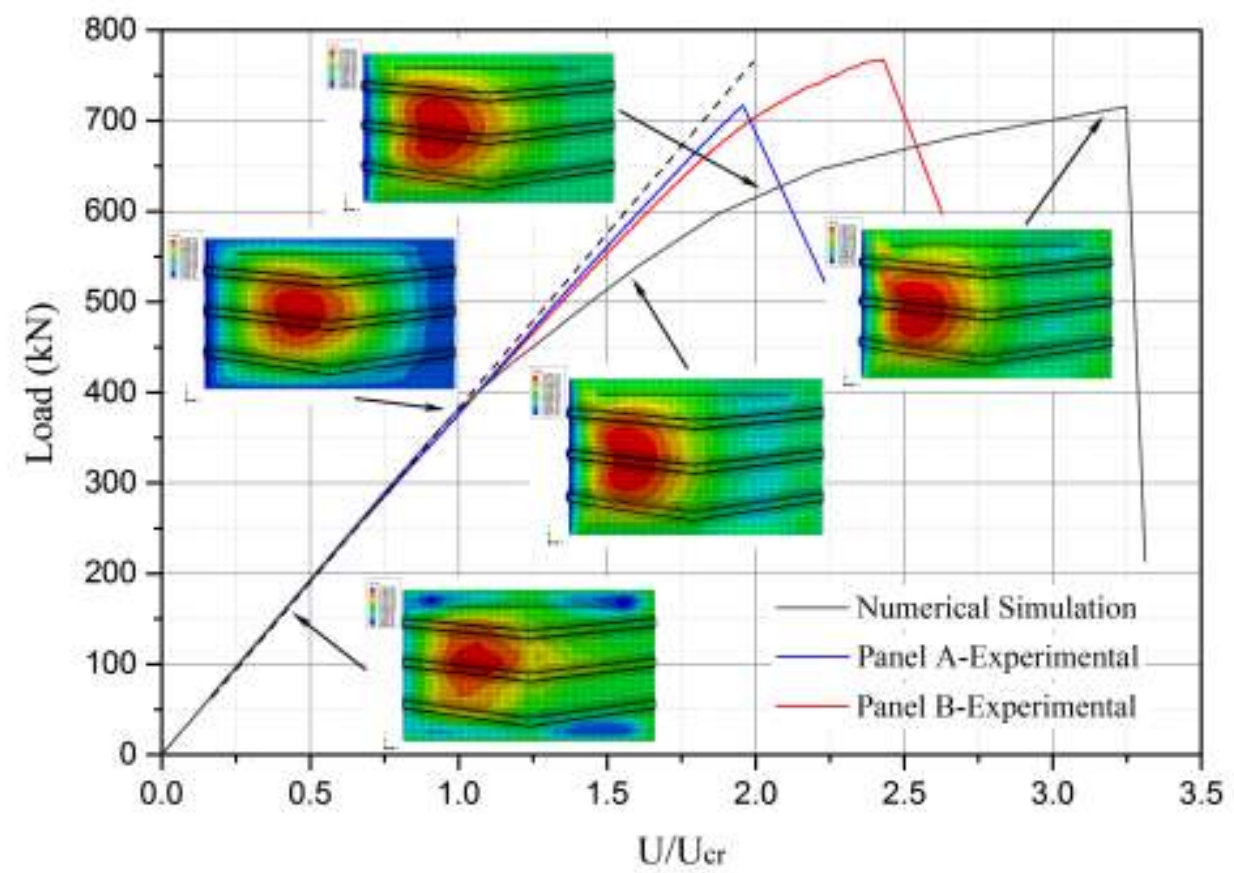

Fig.11. Comparison between the experimental and numerical normalized load-shorting curves

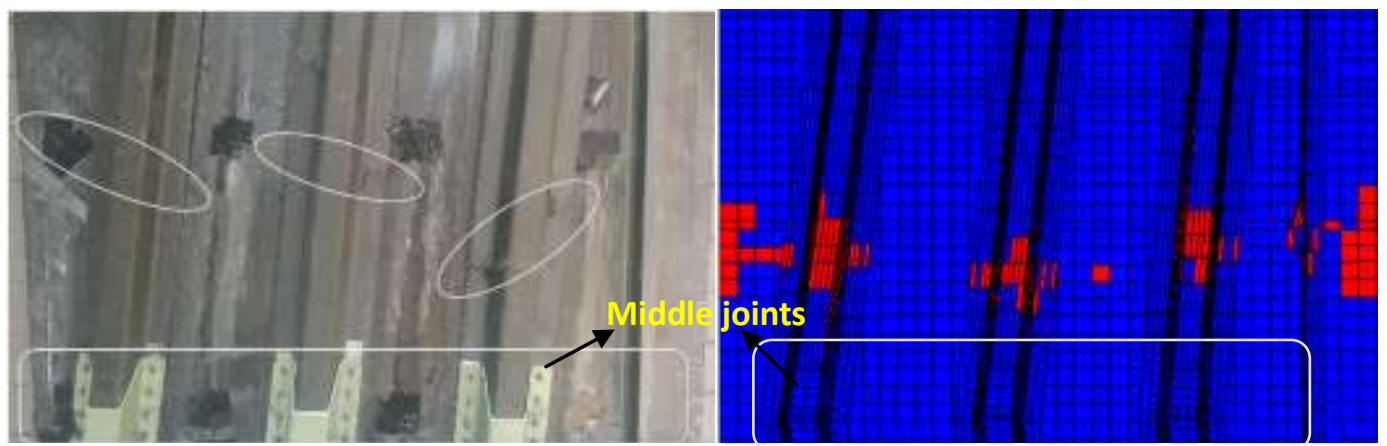

(a) Fiber damage of the panel
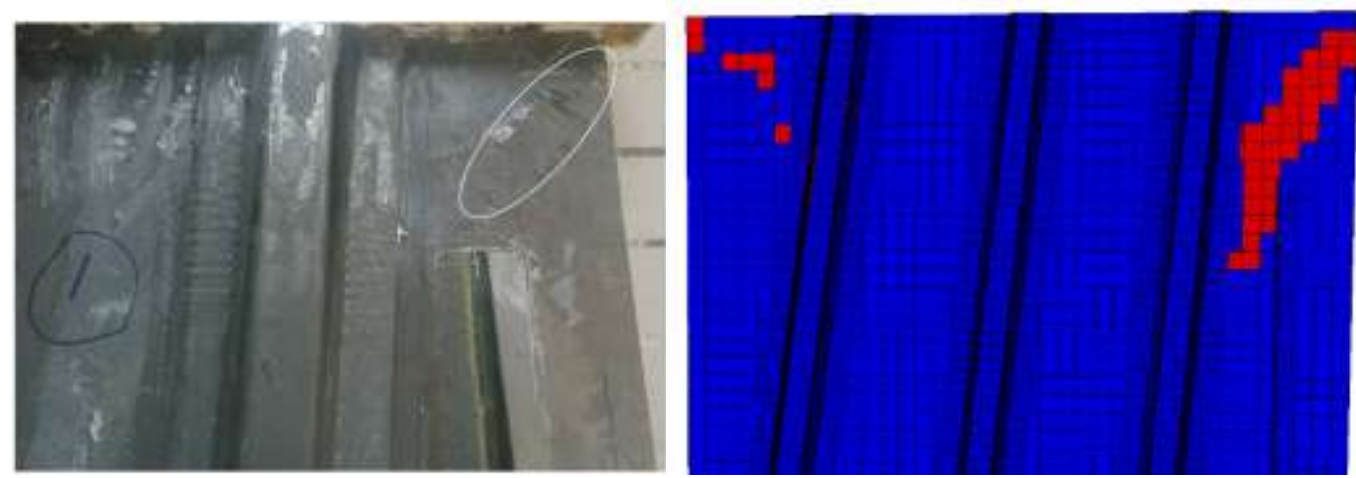
(b) Matrix damage of the panel

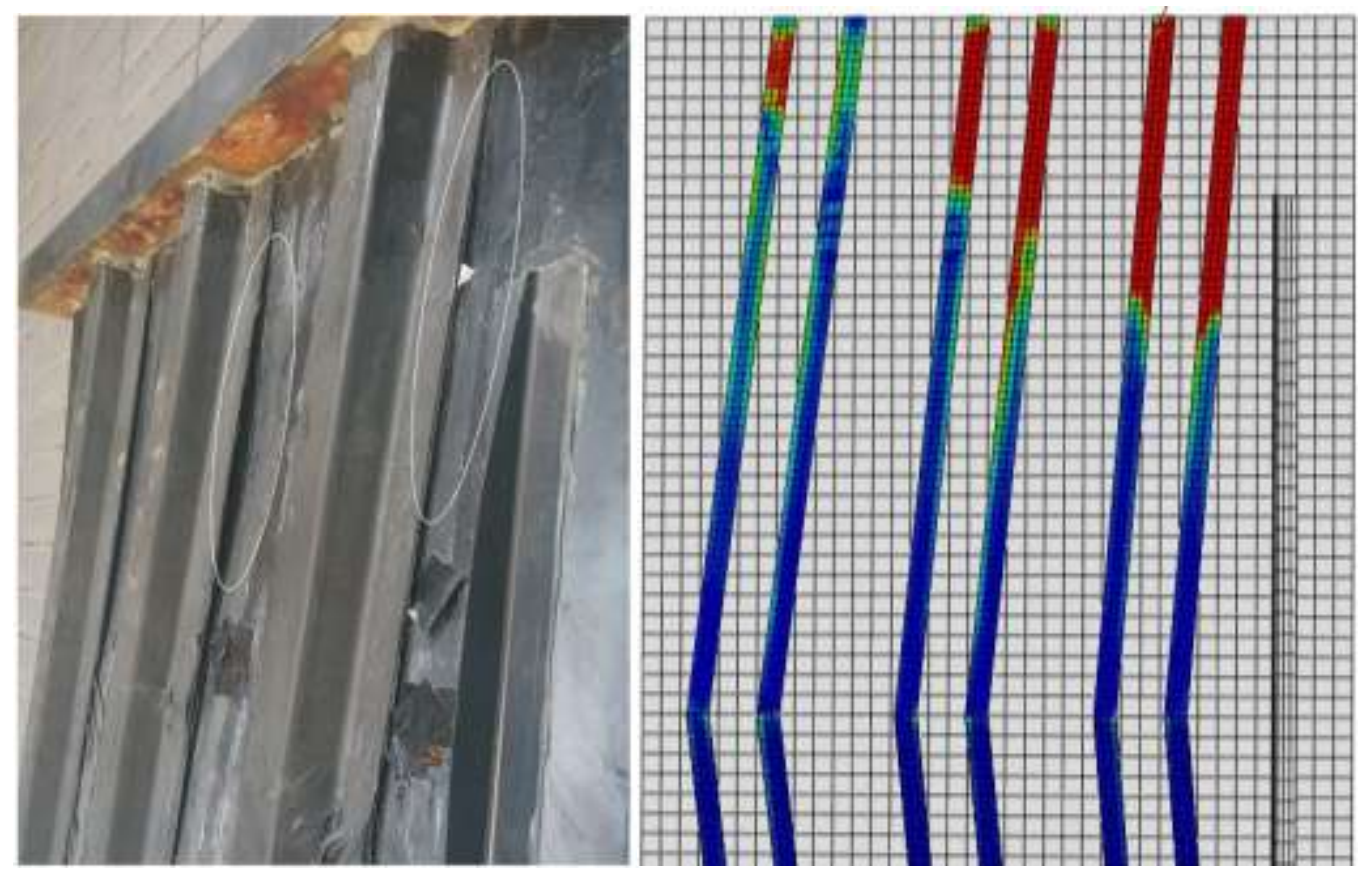

(c) Delamination of the panel

Fig. 12. Collapse state of the panel 


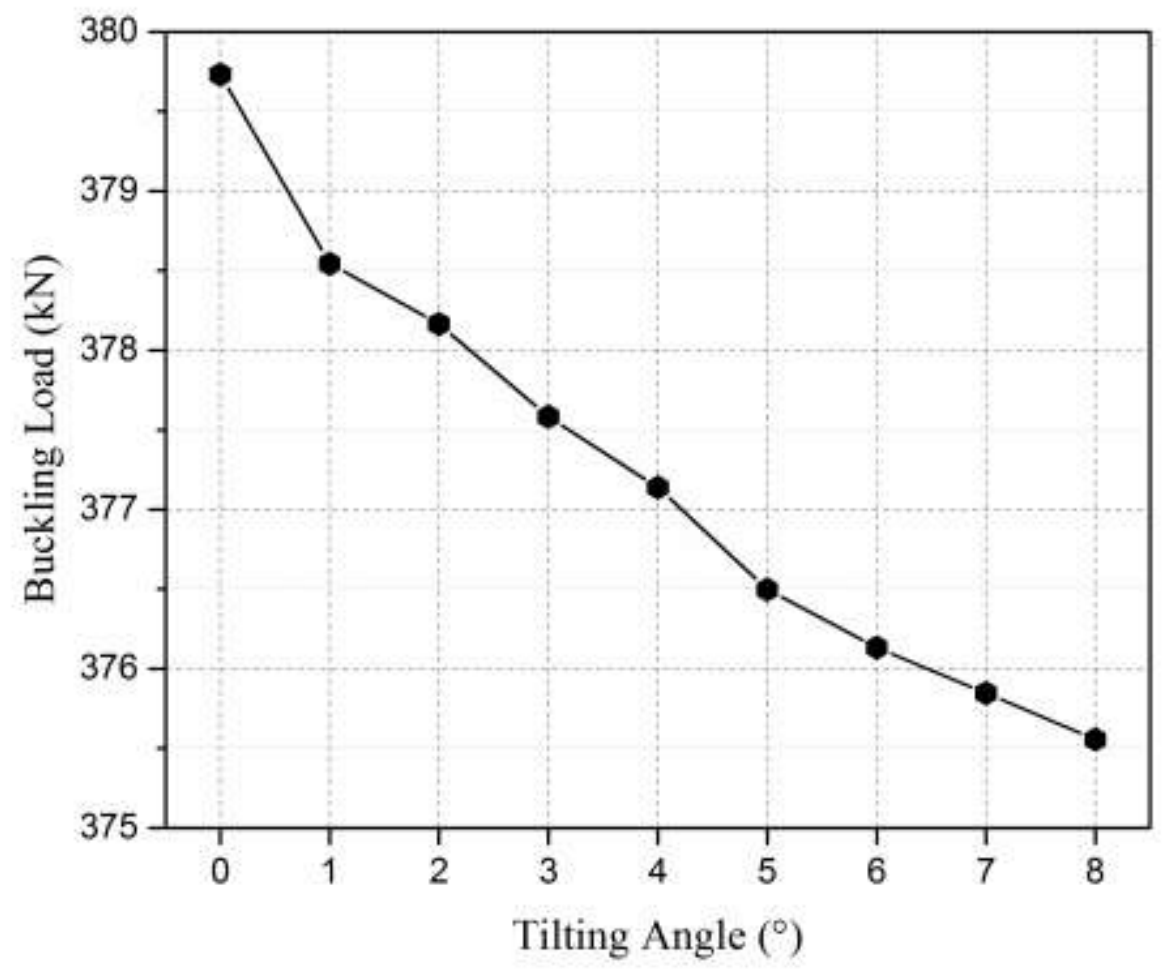

Fig. 13(a).Variation of the buckling loads with the changing of tilting angles

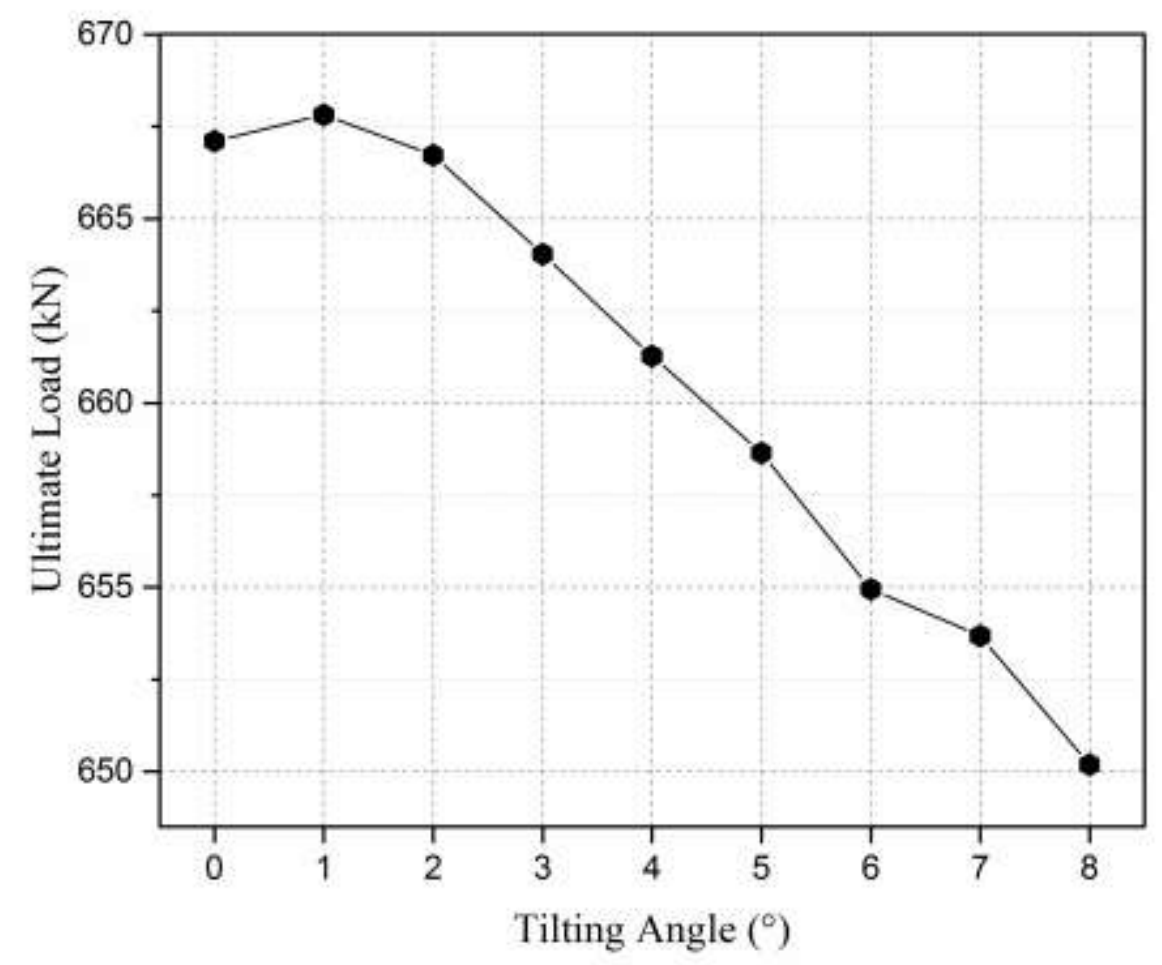

Fig. 13(b). Variation of the ultimate loads with the changing of tilting angles 